\title{
Opinion
}

\section{Advancing challenges in Paediatric Virology: An interview with Professor Barbara A. Rath, Co-founder and Chair of the Vienna Vaccine Safety Initiative}

\author{
IOANNIS N. MAMMAS ${ }^{1-3}$ and DEMETRIOS A. SPANDIDOS ${ }^{1}$ \\ ${ }^{1}$ Laboratory of Clinical Virology, School of Medicine, University of Crete, 71003 Heraklion; ${ }^{2}$ First Department of Paediatrics, \\ University of Athens School of Medicine, 11527 Athens; ${ }^{3}$ Paediatric Clinic, Aliveri, 34500 Island of Euboea, Greece
}

Received July 22, 2019; Accepted August 26, 2019

DOI: $10.3892 /$ etm.2019.7948

\begin{abstract}
The Vienna Vaccine Safety Initiative (ViVI) is an international, scientific, non-profit, research organization, which aims to promote research, clinical practice and communication on Paediatric Infectious Diseases (PID) in a globalized healthcare setting, to facilitate the implementation of high standards in vaccine safety and efficacy and to support international and interdisciplinary scientific collaboration. Professor Barbara A. Rath, Chair and Co-founder of the Vienna Vaccine Safety Initiative, advocates for the establishment of global research networks in the field of neonatal and paediatric viral infections. Viruses do not respect borders, and large datasets are required and joint action is necessary to further strengthen efforts towards viral diseases eradication and prevention. She encourages the paediatric community to embrace the new opportunities technology offers for healthcare and medical education. To date, the Vienna Vaccine Safety Initiative has developed a number of innovative mobile applications and diagnostic tools, such as the 'VAccApp', which helps parents understand which vaccines were administered to their children, the 'ViVI Disease Severity Score', which measures clinical severity in patients with acute respiratory infections and flu-like illnesses, the 'VACC Tool', which assesses patient's clinical presentation to a set of diagnostic algorithms for adverse events following immunization and the 'ViVI Health Survey', which enables children and young adults on the move to report health needs securely and confidentially. Professor Rath agrees that during this decade there is momentum in the field of Paediatric Virology, as new antivirals and vaccines emerge and are finally becoming available to children. In the future, 'in-house' specialists for Paediatric Virology could be helpful to provide
\end{abstract}

Correspondence to: Professor Demetrios A. Spandidos, Laboratory of Clinical Virology, School of Medicine, University of Crete, 71003 Heraklion, Greece

E-mail: spandidos@spandidos.gr

Key words: Barbara A. Rath, Paediatrics, Paediatric Virology, medical education, Vienna Vaccine Safety Initiative, Precision Medicine, mobile health quality of care and reduce antimicrobial resistance by providing individual as well as hospital-wide consultations and advice. She estimates that Paediatric Virology will eventually find its place in the context of PID and Vaccinology.

\section{Contents \\ 1. Introduction \\ 2. Questions and Answers}

\section{Introduction}

Professor Barbara A. Rath, MD, PhD, HDR (Fig. 1), is a board-certified Paediatrician and Infectious Diseases Specialist with more than 20 years of experience in clinical trials, Public Health and Virology in the USA, Latin America and Europe. Professor Rath is an Honorary Professor at Nottingham School of Medicine (Nottingham, UK) and Research Director at the University of Bourgogne-Franche-Comté (Besançon, France). She received her medical education in Germany, the USA and Spain, and her doctoral degrees and habilitation from the University of Basel in Switzerland and the University of Bourgogne-Franche-Comté in France. In addition to a post-doctoral fellowship at the Stanford School of Medicine at the Division of Infectious Diseases and Geographic Medicine (California, USA), she received paediatric residency and infectious diseases subspecialty training at Duke University in Durham (North Carolina, USA) and Tulane University in New Orleans (Louisiana, USA). In 2018, she completed the Global Paediatrics Leadership Programme at Harvard Medical School in Boston (Massachusetts, USA). Professor Rath chairs the Epidemiology Group for the International Society for Influenza and Other Respiratory Viruses (ISIRV) and is (ex-officio) board member for ISIRV. She also serves on the board for the European Society for Clinical Microbiology and Infectious Diseases (ESCMID) Study Group for Respiratory Viruses (ESGREV). Recent research focuses on defining a Precision Medicine approach to managing acute viral infections in children. By combining the innovation technique of Design Thinking with scientific scrutiny, she developed digital real-time surveillance 
programmes and quality improvement programmes for the management of respiratory viral infections in collaboration with regulatory and public health agencies.

Professor Rath is Co-founder and Chair of the Vienna Vaccine Safety Initiative (ViVI; www.vi-vi.org), an international think tank and non-profit-organization focused on new avenues for the treatment, communication and prevention of Paediatric Infectious Diseases (PID). Her team developed and validated clinical and virologic endpoints and mobile applications or clinical trials and observational settings. The goal is to individualize the management of influenza and other respiratory viral infections though the integration of PID epidemiology with data standardization, e-health, biomarker research and advanced diagnostic capabilities. Members of the Vienna Vaccine Safety Initiative include experts in information technology, data standards, risk communication, global health, population science, health policy, bioethics and regulatory science. The Vienna Vaccine Safety Initiative is a founding member of the International Association of Innovation Professionals (IAOIP) and an institutional member of the European Forum for Good Clinical Practice (EFGCP), the European Union-Joint Action on Vaccination (EU-JAV) and the EU Coalition for Vaccination.

In the context of the '5th workshop on Paediatric Virology', which will be held in Sparta (Greece), Professor Rath will give her plenary lecture on the understanding of the burden of respiratory syncytial virus (RSV) and influenza infections in real-time and she will present results from the European pilot project entitled 'Partnering for Enhanced Digital Surveillance of Influenza-like Disease and the Effectiveness of Antivirals and Vaccines' (PEDSIDEA). She will also receive by the Paediatric Virology Study Group (PVSG) the '2019 Paediatric Virology Award' for her outstanding academic, research and clinical contribution in Paediatric Virology.

\section{Questions and Answers}

Question: What is the Vienna Vaccine Safety Initiative and which are its principal aims?

Answer: The Vienna Vaccine Safety Initiative is an international scientific think tank and non-profit research organization. Our principal aims are: i) To promote evidence-based and science-informed infectious diseases and vaccine safety research and communication; ii) to stimulate thinking around key concepts and drive innovation in a globalized healthcare setting; iii) to facilitate the implementation of high standards in vaccine safety and efficacy; and iv) to provide a platform for international and interdisciplinary scientific collaboration in infectious diseases and vaccines. When the ViVI scientific think tank was initially launched in 2008 in Vienna, Austria, this was done out of a shared concern over an increasingly polarized vaccine debate. As scientists and subject matter experts studying various aspects of vaccines and immunization, we decided that we needed to do a better job at working together and communicating what we know, and how we know it. We took an innovative, person-cantered approach. The think tank was designed to include experts in Clinical Medicine (e.g., Paediatrics, PID, Family Medicine, Internal Medicine and Dermatology), Virology, Vaccine Research and Development, Basic Sciences, Epidemiology, Linguistics,

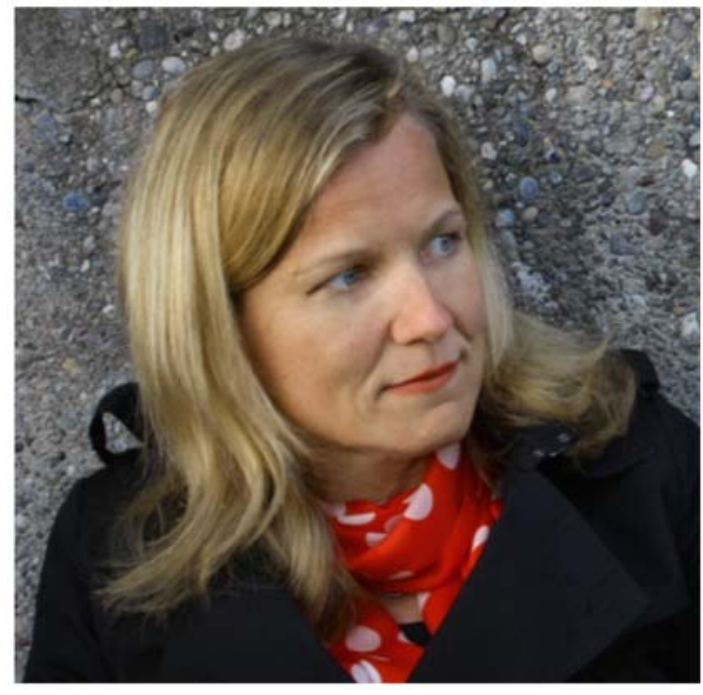

Figure 1. Professor Barbara Rath, Co-founder and Chair of the Vienna Vaccine Safety Initiative (Berlin, Germany) and Chair of the '5th workshop on Paediatric Virology', Sparta, Greece, October 12, 2019.

Information Technology, Medical Anthropology, Data Standards, Regulatory Science and Bioethics. For new ideas, we need all of these disciplines, and the scientific knowledge that is available to us needs to be translated into measurable benefits for the people we serve.

Question: Despite the growing evidence supporting the safety and the effectiveness of recommended vaccines, over the past decades, some parents have become reluctant to have their children fully vaccinated. What are the most frequent reasons for parental vaccination concerns and hesitance? How can this be improved?

Answer: The reasons for vaccine hesitancy are complex and vary in different cultures and sociodemographic groups. One of our first research projects was to assess vaccine safety perceptions in Vienna, Austria. A team of doctoral students worked with us to conduct a survey among parents picking up their children from kindergarten. The survey instrument was originally designed by the US Centres for Disease Control and Prevention (CDC) and adopted to the Austrian healthcare system. We assessed parents across all city districts covering different sociodemographic strata. We found that influenza vaccine was the least trusted vaccine. The main reasons for vaccine refusal were concerns over the safety and/or necessity (i.e., efficacy) of a vaccine. An intact parent-physician relationship was the most important factor linked to trust in vaccines (1). Physicians, especially paediatricians, were the most trusted sources of vaccine information, whereas many online sources and television reports were perceived as 'fear-mongering'. Incidentally, this project was completed right before the first news about the 2009/10 influenza pandemic broke. We cannot approach parents' concerns with a 'one serves-all approach'. Ideally, vaccine consultations should be provided by well-trained healthcare professionals, who are both knowledgeable about the topic and willing to listen (2). During vaccine conversations, it is important to bear in mind that parents usually weigh the individual good (i.e., the expected benefits to their child) above the common good (3). 
Question: Acute respiratory infections represent common paediatric emergencies and their accurate diagnosis is necessary for their management and control. Can we clinically distinguish respiratory viral infections based on clinical symptoms and signs?

Answer: It is interesting that most paediatricians have a basic idea of 'how influenza looks like clinically', as opposed to other types of viral infection. Most textbooks still teach these concepts without much evidence to back them up. We were interested in challenging these concepts, and we investigated whether paediatric respiratory viral infections could be discriminated based on a patient's symptoms. We conducted an extensive literature review looking for symptoms linked to specific respiratory viral infections [PROSPERO No. CRD42017059557]. We compared the results of the literature review to our own observations in a paediatric cohort of ca. 6,000 patients. What we found is that certain symptoms, such as cough, were indeed positively linked to influenza, for example, but they were also linked to other types of respiratory infection, such as RSV, human metapneumovirus and human bocavirus infections. This means that clinical symptoms by themselves do not rule in/out any specific type of respiratory viral infection, i.e., specific symptoms may be observed in one type of infection but also in others, even if less frequently (4). The idea that we can diagnose RSV or other respiratory viral infections 'clinically' may indeed be a myth.

Question: How frequent is the underreporting of acute respiratory infections, such as influenza and RSV, in hospital based-surveillance? What can be the value of specific sensitive rapid tests, e.g., RSV or influenza, as well of the modern molecular Virology diagnostic tools? How difficult is surveillance of viral infections at a national or international level?

Answer: The underreporting of respiratory viral infections in hospitals is probably quite common. Hospital-based surveillance systems often use one or several of the following parameters to estimate RSV or influenza incidence rates: International Classification of Diseases (ICD)-coding, hospital laboratory reports, or clinical case definitions. In a quality improvement (QI) programme in Berlin in collaboration with the National Reference Centre for Influenza at the Robert Koch institute, we established a QI team (independent from routine care) that would assess all influenza-like illness (ILI) patients taking samples to be tested for respiratory viruses. We learned that without the QI system in place, we would have missed the majority of specific respiratory viral diagnoses (5). Among 6,073 individuals with ILI qualifying for the QI programme, only $8.7 \%(528 / 6,073)$ would have undergone virus diagnostics during routine care. Emergency room surveillance based on ICD codes would have missed $61 \%(359 / 587)$ of influenza diagnoses. Less than half $(49.6 \%$, 398/802) of all RSV cases received RSV-specific ICD codes (such as J20.5: 'acute bronchitis due to RSV') (5). Considering these challenges, we were interested in the question whether point of care testing could help us make accurate diagnoses more quickly and also to make the test results known to the patients and their caretakers while they were still with us in the Emergency Department (ED) (6). Knowing the rate of 'break through cases' is important for the evaluation of antivirals and vaccines. We found that newer, second-generation rapid tests can be quite useful, especially in children (7-9). The US Food and Drug Administration (FDA) recently lifted the sensitivity thresholds for rapid diagnostic tests (10). Rapid tests meeting these new standards can be used without hesitation. We are always on the look-out for novel technologies, such as rapid tests that could inform us about antiviral drug resistance, for example. Considering that treatment options will be expanding in the near future, we will need to adjust best practices. For more timely and comprehensive surveillance we need to include both, high and low resource settings. This requires diagnostic tests that are affordable, easily shipped and set up, highly accurate and simple to perform (i.e., Clinical Laboratory Improvement Amendments (CLIA) - waived). It should be possible to test specimens individually and in batches (adjusting to patient numbers). Most importantly, we need health economic analyses evaluating their performance in antibiotic stewardship and QI programmes.

Question: Antiviral agents are frequently underused or misused, while in several cases of children with viral infections antibiotics are prescribed. What do you believe that are the reasons for this and how can this change?

Answer: In our experience in Berlin, antivirals were hardly ever used in routine care. Not all paediatricians are comfortable with antiviral prescribing. Also, there seems to be significant delay between the time when new antivirals are licensed for adults and the time when they become available to the paediatric age group. Until recently, for example, there has not been any licensed influenza antiviral medication available for infants and neonates, who are among the most vulnerable risk groups. Paediatricians and neonatologists need to move the field forward with clinical trials in infants and children (11-13). Meanwhile, the design of paediatric clinical trials is increasingly complex. We need to create consensus on what we want to achieve with an intervention. The objectives of treating chronic viral infections, which may reactivate throughout a patient's lifetime, are quite distinct from acute viral infections. The dynamics of resistance development are different in DNA and RNA viruses $(14,15)$. As new treatment options become available, we will need to study and evaluate risk/benefit in different settings and populations. Tom Merigan recently highlighted the fact that 'HIV provided one of the first examples of personalized Medicine' (personal communication). Maybe, we will use more combination therapies in the future along with individualized treatment plans. Some viral diseases may become vaccine preventable and treatable at the same time. This means that paediatricians must be trained to take a patient's clinical severity and individual risk factors into account (6) and to administer the best treatment at the right time. Rapid diagnostics will help us adjust our decisions quickly, while the patient is still in front of us (9). Unnecessary 'random' antimicrobial use must be avoided. Paediatricians need to be more confident at withholding antimicrobials in cases where there is no evidence of a treatable cause (16). Instead, we will need to look for specific diagnoses to guide our management decisions and communication. Implementation research and health economic analyses will help us develop strategies that are beneficial to the individual and the environment. 
Question: Recently, your team has proposed innovative mobile applications to improve quality of care. How influential can the usage of modern technology be in medical education and paediatric health practice? How can it be used by our patients and their parents?

Answer: It is fascinating to see what can be achieved if we embrace the opportunities technology offers for healthcare and medical education. Technological innovation can go both ways: It can drive us further apart and it can bring us closer together. The Vienna Vaccine Safety Initiative created a number of innovative ideas using 'Design Thinking', an innovation technique placing the end-user at the core of the development process (17). Interdisciplinary team work, rapid prototyping, multiple iterations and rigorous research lead to the development of digital tools that hold up to scientific scrutiny (18). One example is the 'VAccApp', a mobile application helping parents understand which vaccines were administered to their children (19). Current immunization records are not easily comprehensible $(17,20)$. If parents were empowered by an app to make use of their child's vaccination card while spending time in a waiting room for example, they could then provide accurate information to the doctor and ask questions where necessary (19). Another set of digital tools are directed at healthcare professionals. The Vienna Vaccine Safety Initiative Disease Severity Score ('ViVI Score', https://score.vi-vi.org) helps doctors to measure clinical severity in patients with acute respiratory infections and flu-like illness $(16,21,22)$. Being able to compare severity over time and/or across cohorts is useful in hospital-based QI programmes but also in multi-centre networks, such as PEDSIDEA (Partnering for Enhanced Digital Surveillance of Vaccines and the Effect of Antivirals and Vaccines) (23). Another app, the 'VACC Tool', helps doctors to assess a patient and to compare their clinical presentation to a set of diagnostic algorithms for adverse events following immunization $(24,25)$. Digital tools may therefore help doctors to apply scientific evidence and to make precision Medicine accessible at the point of care (26). It is hoped that mobile apps may also help reduce the under-reporting of rare adverse events and/or infectious/immunological conditions to regulatory authorities (27-31). More recently, we are also collaborating with patient representative organizations to develop patient reported outcome measures giving a voice directly to children and their families (2). One example is the 'ViVI Health Survey', a digital tool helping children and adolescents on the move to report health needs securely and confidentially $(32,33)$.

Question: You have been involved actively in assessing and evaluating health needs among migrants, especially children and adolescents. What are the lessons that you received as a paediatric health professional supporting migrant and refugee populations? Have you participated in any humanitarianism mission in the Greek islands?

Answer: The large number of children and adolescents that are either displaced or on the move at this point in time, should be a concern to all paediatricians $(34,35)$. The experience of displacement and migration during childhood harbours unique challenges. Oftentimes, the decision was not theirs to take, but being displaced or on the move means that children are separated from a familiar environment. Not all children cope with this experience equally (36). I did not have the opportu- nity to participate in humanitarian missions in Greece at the time, but I served a group of children and their families at a paediatric clinic inside one of the larger shelters for people seeking refuge in Berlin in 2015/16. Providing continuity of care is important to individuals who have not experienced stability in a while. During the first weeks after arrival, acute infections and injuries were common complaints. It took time to build trust allowing families to feel sufficiently safe to discuss other health-related concerns with me. The children's cheers were the first sign of normalcy lifting their parent's spirits along with everyone else's. There was always a group of teenagers at the clinic after school offering to help, translating for families, or asking for books to read. Their desire to contribute was humbling and their hunger for education right-out amazing.

Question: To date, you have encouraged with enthusiasm the establishment of international scientific networks and you have participated in several global research collaborations. How useful and how difficult are international collaborations in our field?

Answer: When it comes to infectious diseases and disease prevention, international collaboration is important. We know that viruses do not respect borders. Unless we work together, we will not succeed. Networks help us to study new and emerging pathogens $(37,38)$, to improve the management of 'established' viral infections, and to contain those making a comeback due to gaps in vaccination coverage (such a measles). Vaccine research and development is not possible without large datasets. The development of antiviral therapy for people living with HIV/AIDS would have been unconceivable without international collaboration. HIV/AIDS also triggered a new level of patient engagement. We should be encouraged by the success of joint action. Many viral infections have become vaccine preventable, and we need to further strengthen efforts towards disease eradication and prevention.

Question: By which values/virtues have you been inspired in your career? What is the key of your clinical, research and academic success?

Answer: This question reminds me of a winter semester spent at the National and Kapodistrian University of Athens, where I surveyed medical students about their perceptions of the Hippocratic Oath (39). One of the questions asked was 'which criteria do you find most important in your medical practice: personal convictions, inter/national law, or professional codes?'. It is a difficult question. In most cases it is a mixture of the above and we hope they never get into conflict with one another. One of my favourite places to learn during medical school was the Institute of Medical History. Here, we heard about the trials and tribulations of our profession, but also about its very best moments. We learned to work with people from other disciplines discussing topics that have no simple yes/no answers. What is the significance of historical documents such as the Hippocratic Oath, the Prayer of Maimonides (40), or the Geneva Convention (41) in a 'post Hippocratic Era' (42), where we struggle with the role of pluralism (43), professionalism $(44,45)$, paternalism $(46,47)$, scientific progress and digital Medicine in society (48-50)? During my final semester, we focused on the Nuremberg Trials $(51,52)$ studying court 
proceedings (53), visiting the Palace of Justice building, learning about health-related propaganda during the 1930s in Germany, and the conditions leading to a 'Medicine without humanity $(46,54,55)$ '. All of this left a lasting impression. Regardless of religious or political views, we should treat people the same way we would like to be treated in return. We should engage without judgment. What I enjoy most about children, is their low tolerance for pretence. Looking at the history of our profession (including views from the outside) can give us the necessary distance for a critical analysis of current practices and ways to improve them. Some of my favourite reads are 'La Naissance de la Clinique' by Michel Foucault, 'The Doctor's Dilemma' by George Bernard Shaw and the always ironic depictions of 'doctor figures' in Thomas Mann's novels.

Question: German, British or US national health system? Which one do you support as the best in paediatric health care? Answer: This is difficult for me to say as I am not an expert in health systems or economics. Having trained or practiced in seven different counties, I have found positive and negative aspects in each of them. As a paediatrician, I am in favour of any system that provides high-quality care to those who are too young to vote or lobby for themselves. A good healthcare system should allow us to practice in line with the principles of bioethics, including justice i.e., the fair allocation of resources and respect for patient autonomy (56). At the same time, healthcare systems should have sufficient flexibility to allow constant improvements through science and innovation (57).

Question: Paediatric Virology is an increasing educational and clinical challenge. New antiviral agents and vaccines are still expected; new viruses are emerging, while specific groups of patients, such Paediatric Intensive Care Unit (PICU) patients, transplant children, HIV patients, migrant and refugee children require advanced health care support. What are the most important needs in the field of paediatric viral infections that should be solved in the near future?

Answer: There is momentum in the field of Paediatric Virology as new antivirals and vaccines emerge and are finally becoming available to children. Basic knowledge about the mechanisms of drug resistance and a one-health approach to Medicine along with new indications for treatment and prevention should be taught in medical school. When treating influenza infections in infants for example, a lag in virologic response could be an early indicator for resistance development (14). This resembles experiences made with the use of antiretrovirals (58-60). Whenever we think about antiviral resistance development, we need to check for adequate dosing and routes of administration. In severe cases, parenteral use of antivirals may be preferential (22). In other instances, we need to adjust the duration of treatment (9). The dynamics of paediatric host responses to viral infection are yet to make their way into medical school and residency training curricula.

Question: Recently, we have proposed Paediatric Virology as a separate paediatric subspecialty (61). Based on your clinical and academic experience in different health systems in the world, how significant can be the role of paediatric virologists in the prevention, management and academic teaching of neonatal and paediatric viral infections?

Answer: Your proposal can be characterized as a call for innovation in paediatric education. Having a specialist for Paediatric Virology 'in-house', who has the time and resources to provide individual as well as hospital-wide consultations and advice, may well be cost-effective in the long run. Dealing with viral infections in children requires specific know-how, but we need specialists that do to not forget the big picture. Those of us who ended up specializing on the prevention, management and academic teaching of neonatal and paediatric viral infections have followed very different paths in order to get there. In my case, the starting point was a combined internship programme. I worked at the Infectious Diseases Outpatient Unit in the mornings and ended the day at the Institute of Virology. As a result, I caught fire for bench-to-bedside research. This led to a journey from the lab to translational science, to clinical training and sub-specialization, back to the lab, to Public Health and clinical research. When I began teaching, I observed a great interest in Paediatric Virology and international health among young scientists, and I wished there had been a specific subspecialty for my students when they finished their thesis. Paediatric Virology will likely find its place in the context of PID and vaccinology. As part of the EU Coalition for Vaccination, the Vienna Vaccine Safety Initiative recently teamed up with the European Academy of Paediatrics (EAP) to facilitate vaccine-related education. We need a paediatrician's workforce with new skills and a global mindset to meet the challenges of the future.

Question: Thank you for your answers as well as your co-chairship and your plenary lecture at our workshop in October in Sparta, Greece.

\section{Acknowledgements}

This article is published in the third supplement issue of the Experimental and Therapeutic Medicine, which is dedicated to Paediatric Virology. This edition is performed in the context of the '5th workshop on Paediatric Virology' (Sparta, Greece, October 12, 2019) organized by the Paediatric Virology Study Group (PVSG) and supported by the Department of Clinical Virology of the University of Crete School of Medicine and the First Department of Paediatrics of the University of Athens School of Medicine. We would like to thank Professor Barbara A. Rath for this educational and inspirational interview-style article. We would also like to thank all the members of the PVSG for their interesting questions to Professor Rath and their valuable comments.

\section{References}

1. Kundi M, Obermeier P, Helfert S, Oubari H, Fitzinger S, Yun JA, Brix M and Rath B: The impact of the parent-physician relationship on parental vaccine safety perceptions. Curr Drug Saf 10: 16-22, 2015.

2. Holt D, Bouder F, Elemuwa C, Gaedicke G, Khamesipour A Kisler B, Kochhar S, Kutalek R, Maurer W, Obermeier P, et al: The importance of the patient voice in vaccine safety and immunization - are we listening? ESCMID 22 (Suppl 5): S146-153, 2016. 
3. Bouder F: Benefit/risk communication by the European Medicines Agency: a study of influential stakeholders expectations and attitudes 2011. European Medicines Agency (EMA), London, 2011. https://www.ema.europa $\mathrm{eu} / \mathrm{en} / \mathrm{documents} / \mathrm{report} / \mathrm{benefit} /$ risk-communication-europeanmedicines-agency-study-influential-stakeholders-expectationsattitudes_en.pdf. Accessed May 20, 2019.

4. Ma X, Âlchikh M, Conrad T, et al: Can we Distinguish Respiratory Viral Infections based on Clinical Symptoms? Lessons from a Pediatric Inception Cohort. In: Proceedings of the ASM2017 Microbe - American Society for Microbiology Conference, New Orleans, LA, 2017.

5. Alchikh M, Conrad T, Hoppe C, Broberg E, Penttinen P, Reiche J, Biere B, Schweiger B and Rath B: Are we missing respiratory viral infections in infants and children? Comparison of a hospital-based quality management system with standard of care. ESCMID 25: 380.e9-.380.e16, 2019.

6. Rath B, Tief F, Karsch K, Muehlhans S, Obermeier P, Adamou E, Chen X, Seeber L, Peiser C, Hoppe C, et al: Towards a personalised approach to managing influenza infections in infants and children - food for thought and a note on oseltamivir. Infect Disord Drug Targets 13: 25-33, 2013.

7. Tuttle R, Weick A, Schwarz WS, Chen X, Obermeier P, Seeber L, Tief F, Muehlhans S, Karsch K, Peiser C, et al: Evaluation of novel second-generation RSV and influenza rapid tests at the point of care. Diagn Microbiol Infect Dis 81: 171-176, 2015.

8. Rath B, Tief F, Obermeier P, Tuerk E, Karsch K, Muehlhans S, Adamou E, Duwe S and Schweiger B: Early detection of influenza $\mathrm{A}$ and $\mathrm{B}$ infection in infants and children using conventional and fluorescence-based rapid testing. J Clin Virol 55: 329-333, 2012

9. Chen X, Pouran Yousef K, Duwe S, Karsch K, Grover S, Wählisch S, Obermeier P, Tief F, Mühlhans S, Seeber L, et al: Quantitative influenza follow-up testing (QIFT) - a novel biomarker for the monitoring of disease activity at the point-of-care. PLoS One 9: e92500, 2014.

10. CDRH Microbiology Devices Advisory Committee Meeting. Executive Summary: Proposed reclassification of the rapid influenza detection tests. Food and Drug Administration, Gaithersburg, MD, 2013. http:// www.fda.gov/downloads/AdvisoryCommittees /Committees MeetingMaterials/ MedicalDevices/ MedicalDevices AdvisoryCommittee/ MicrobiologyDevicesPanel/UCM356185. pdf. Accessed September 28. 2013.

11. Rath B, Blumentals W, Miller K, Starzyk K, Tetiurka B and Wollenhaupt M: A prospective observational study of oseltamivir safety and tolerability in infants and young children $\leq 24$ months. Pharmacoepidemiol Drug Saf 24: 286-296, 215.

12. Rath B, Brzostek J, Guillén S, Niranjan V, Chappey C, Rayner C and Clinch B: Safety, virology and pharmacokinetics of oseltamivir in infants with laboratory-confirmed influenza infection: A Phase I/II, prospective, open-label, multi-center clinical trial Antivi Ther 20: 815-825, 2015.

13. Kamal MA, Acosta EP, Kimberlin DW, Gibiansky L, Jester P, Niranjan V, Rath B, Clinch B, Sánchez PJ, Ampofo K, et al: The posology of oseltamivir in infants with influenza infection using a population pharmacokinetic approach. Clin Pharmacol Ther 96: 380-389, 2014.

14. Rath B, von Kleist M, Tief F, Karsch K, Tuerk E, Muehlhans S, Louis F, Skopnik H, Schweiger B and Duwe S: Virus load kinetics and resistance development during oseltamivir treatment in infants and children infected with Influenza A(H1N1) 2009 and Influenza B viruses. Pediatr Infect Dis J 31: 899-905, 2012.

15. Rath B, Chen X, Spies V, Muehlhans S, Obermeier P, Tief F, Seeber L, Karsch K, Milde J, Skopnik H, et al: Prospective surveillance of antiviral resistance in hospitalized infants less than 12 months of age with $\mathrm{A}(\mathrm{H} 3 \mathrm{~N} 2)$ influenza infection and treated with oseltamivir. Antivir Ther 22: 515-522, 2017.

16. Tief F, Hoppe C, Seeber L, Obermeier P, Chen X, Karsch K, Mühlhans S, Adamou E, Conrad T, Beresniak A, et al: An inception cohort study assessing the role of pneumococcal and other bacterial pathogens in children with influenza and ILI and a clinical decision model for stringent antibiotic use. Antivir Ther 21: 413-424, 2016.

17. Seeber L, Michl B, Rundblad G, Trusko B, Schnjakin M, Meinel C, Weinberg U, Gaedicke G and Rath B: A design thinking approach to effective vaccine safety communication. Curr Drug Saf 10: 31-40, 2015.

18. Rath B: Vienna Vaccine Safety Initiative. Hum Vaccin Immunother 14: 1038-1041, 2018.
19. Seeber L, Conrad T, Hoppe C, Obermeier P, Chen X, Karsch K, Muehlhans S, Tief F, Boettcher S, Diedrich S, et al: Educating parents about the vaccination status of their children: A user-centered mobile application. Prev Med Rep 5: 241-250, 2017.

20. Maurer W, Seeber L, Rundblad G, Kochhar S, Trusko B, Kisler B, Kush R and Rath B; Vienna Vaccine Safety Initiative: Standardization and simplification of vaccination records. Expert Rev Vaccines 13: 545-559, 2014.

21. Rath B, Conrad T, Myles P, Alchikh M, Ma X, Hoppe C, Tief F, Chen X, Obermeier P, Kisler B, et al: Influenza and other respiratory viruses: Standardizing disease severity in surveillance and clinical trials. Expert Rev Anti Infect Ther 15: 545-568, 2017.

22. Karsch K, Chen X, Miera O, Peters B, Obermeier P, Francis RC, Amann V, Duwe S, Fraaij P, Heider A, et al: Pharmacokinetics of Oral and Intravenous Oseltamivir Treatment of Severe Influenza B Virus Infection Requiring Organ Replacement Therapy. Eur J Drug Metab Pharmacokinet 42: 155-164, 2017.

23. Rath B, Maltezou HC, Papaevangelou V, PapagrigoriouTheodoridou MA, Alchikh M, Myles P and Schweiger B; PEDSIDEA Network: Partnering for enhanced digital surveillance of influenza-like disease and the effect of antivirals and vaccines (PEDSIDEA). Influenza Other Respir Viruses 13: 309-318, 2019.

24. Hoppe C, Obermeier P, Muehlhans S, Alchikh M, Seeber L, Tief F, Karsch K, Chen X, Boettcher S, Diedrich S, et al: Innovative Digital Tools and Surveillance Systems for the Timely Detection of Adverse Events at the Point of Care: A Proof-of-Concept Study. Drug Saf 39: 977-988, 2016.

25. Obermeier P, Muehlhans S, Hoppe C, Karsch K, Tief F, Seeber L, Chen X, Conrad T, Boettcher S, Diedrich S, et al: Enabling Precision Medicine With Digital Case Classification at the Point-of-Care. EBioMedicine 4: 191-196, 2016.

26. Twilt M: Precision Medicine: The new era in medicine. EBioMedicine 4: 24-25, 2016.

27. Muehlhans S, Richard G, Ali M, Codarini G, Elemuwa C, Khamesipour A, Maurer W, Mworozi E, Kochhar S, Rundblad G, et al: Safety reporting in developing country vaccine clinical trials-a systematic review. Vaccine 30: 3255-3265, 2012.

28. Muehlhans S, von Kleist M, Gretchukha T, Terhardt M, Fegeler U, Maurer W, Namazova-Baranova L, Gaedicke G, Baranov A and Rath B: Awareness and utilization of reporting pathways for adverse events following immunization: Online survey among pediatricians in Russia and Germany. Paediatr Drugs 16: 321-330, 2014.

29. Karsch K, Obermeier P, Seeber L, Chen X, Tief F, Mühlhans S, Hoppe C, Conrad T, Böttcher S, Diedrich S, et al: Human Parechovirus Infections Associated with Seizures and Rash in Infants and Toddlers. Pediatr Infect Dis J 34: 1049-1055, 2015.

30. Obermeier PE, Karsch K, Hoppe C, Seeber L, Schneider J, Mühlhans S, Chen X, Tief F, Kaindl AM, Weschke B, et al: Acute Disseminated Encephalomyelitis After Human Parechovirus Infection. Pediatr Infect Dis J 35: 35-38, 2016.

31. McWillimans P and McMillan S: Mobile tools to detect AEs successfully used in Germany. React Wkly 1609: 9, 2016.

32. Myles P, Swenshon S, Haase K, Szeles T, Jung C, Jacobi F and Rath B: A comparative analysis of psychological trauma experienced by children and young adults in two scenarios: Evacuation after a natural disaster vs forced migration to escape armed conflict. Public Health 158: 163-175, 2018.

33. Rath B, Swenshon S, Haase K, Szeles T, Jung C, Jacobi F and Myles P: Using a mobile application to detect health needs among children and adolescents who are newly arrived migrants in Europe. J Public Health (Oxf): Nov 13, 2018 (Epub ahead of print).

34. Esmaili BE: Caravans and Containers: Children on the Move, Immobilized. Pediatrics 142: e20181470, 2018.

35. ISSOP Migration Working Group: ISSOP position statement on migrant child health. Child Care Health Dev 44: 161-170, 2018.

36. Schrier L, Wyder C, Del Torso S, Stiris T, von Both U, Brandenberger J and Ritz N: Medical care for migrant children in Europe: A practical recommendation for first and follow-up appointments. Eur J Pediatr: Jun 26, 2019 (Epub ahead of print).

37. Elemuwa C, Kutalek R, Ali M, Mworozi E, Kochhar S and Rath B; Vienna Vaccine Safety Initiative: Global lessons from Nigeria's ebolavirus control strategy. Expert Rev Vaccines 14: 1397-1400, 2015.

38. Kochhar S, Rath B, Seeber LD, Rundblad G, Khamesipour A and Ali M; Vienna Vaccine Safety Initiative: Introducing new vaccines in developing countries. Expert Rev Vaccines 12: $1465-1478,2013$ 
39. Rath B, Martus P and Wiesemann C: 'Hippocrates is dead, long live Hippocrates?' Medical Students' Perceptions of the Hippocratic Oath, an Investigation at Athens University. First World Congress on Codes in Ethics in Medicine, Freiburg, 1997.

40. Gesundheit B and Hadad E: Maimonides (1138-1204): Rabbi, physician and philosopher. Isr Med Assoc J 7: 547-553, 2005.

41. Marriott IA: The Geneva Convention: humanitarian law and medicine. Can Med Assoc J 118: 565-566, 571-572, 593, 1978.

42. Pellegrino ED: Medical ethics: Entering the post-Hippocratic era. J Am Board Fam Pract 1: 230-237, 1988.

43. Nirta L and Roh H: Cultural diversity should be taught: a reply to UK medical students' view on interacting with multicultural patients. Korean J Med Educ 31: 176-176, 2019.

44. Sieghart P: Professions as the conscience of society. J Med Ethics 11: 117-122, 1985.

45. Wiesing U: The Hippocratic Oath and the Declaration of Geneva: Legitimisation attempts of professional conduct. Med Health Care Philos, pp1-6, 2019.

46. Murphy P: Are patients' decisions to refuse treatment binding on health care professionals? Bioethics 19: 189-201, 2005.

47. Jansen LA and Wall S: Reconsidering paternalism in clinical research. Bioethics 32: 50-58, 2018.

48. Morley J and Floridi L: The Limits of Empowerment: How to Reframe the Role of mHealth Tools in the Healthcare Ecosystem. Sci Eng Ethics: Jun 6, 2019 (Epub ahead of print).

49. Wachter RM, Judson TJ and Mourad M: Reimagining Specialty Consultation in the Digital Age: The Potential Role of Targeted Automatic Electronic Consultations. JAMA: Jun 27, 2019 (Epub ahead of print)

50. No authors listed: Medicine in the digital age. Nat Med 25: 1, 2019.

51. Fullerton Z: The Protection of Individual Inviolability: Nazi Doctors and their Mark on Biomedical Research. SeniorCapstone Projects, Paper 402, 2015. https://digitalwindow.vassar edu/cgi/viewcontent.cgi?article $=1399 \&$ context=senior_capstone. Accessed June 202019

52. Lemaire F: The 60th anniversary of the Nuremberg doctor's trial: Why a so long waiting to implement the Code? Med Sci (Paris) 23: 1063-1067, 2007 (In French).
53. Mitscherlich A and Mielke F: Medizin ohne Menschlichkeit: Dokumente des Nürnberger Ärzteprozesses: FISCHER Taschenbuch, 1989.

54. Proctor RN: Racial hygiene. Medicine under the Nazis. Harvard University Press, Cambridge, MA, 1988.

55. Reis SP, Wald HS and Weindling P: The Holocaust, medicine and becoming a physician: The crucial role of education. Isr J Health Policy Res 8: 55, 2019.

56. Page K: The four principles: Can they be measured and do they predict ethical decision making? BMC Med Ethics 13: 10, 2012.

57. Garattini C, Raffle J, Aisyah DN, Sartain F and Kozlakidis Z: Big Data Analytics, Infectious Diseases and Associated Ethical Impacts. Philos Technol 32: 69-85, 2019.

58. Rath BA, Olshen RA, Halpern J and Merigan TC: Persistence versus reversion of 3TC resistance in HIV-1 determine the rate of emergence of NVP resistance. Viruses 4: 1212-1234, 2012.

59. Rath BA, von Kleist M, Castillo ME, Kolevic L, Caballero P, Soto-Castellares G, Amedee AM, Robinson JE, Katzenstein DK, Van Dyke RB, et al: Antiviral resistance and correlates of virologic failure in the first cohort of HIV-infected children gaining access to structured antiretroviral therapy in Lima, Peru: A cross-sectional analysis. BMC Infect Dis 13: 1, 2013.

60. Rath BA, Yousef KP, Katzenstein DK, Shafer RW, Schütte C, von Kleist M and Merigan TC: In vitro HIV-1 evolution in response to triple reverse transcriptase inhibitors \& in silico phenotypic analysis. PLoS One 8: e61102, 2013.

61. Mammas IN, Greenough A, Theodoridou M and Spandidos DA: Paediatric Virology: A new paediatric subspecialty? A proposal at the Workshop on Paediatric Virology, Athens, October 10, 2015. Exp Ther Med 11: 3-5, 2016.

This work is licensed under a Creative Commons Attribution-NonCommercial-NoDerivatives 4.0 International (CC BY-NC-ND 4.0) License. 